\section{Psicoterapia de orientação analítica: fundamentos teóricos e clínicos}

\author{
C. L. Eizirik, R. W. Aguiar, S. S. \\ Schestatsky et al. \\ Porto Alegre, Artmed, 2005
}

\author{
José T. Thomé*
}

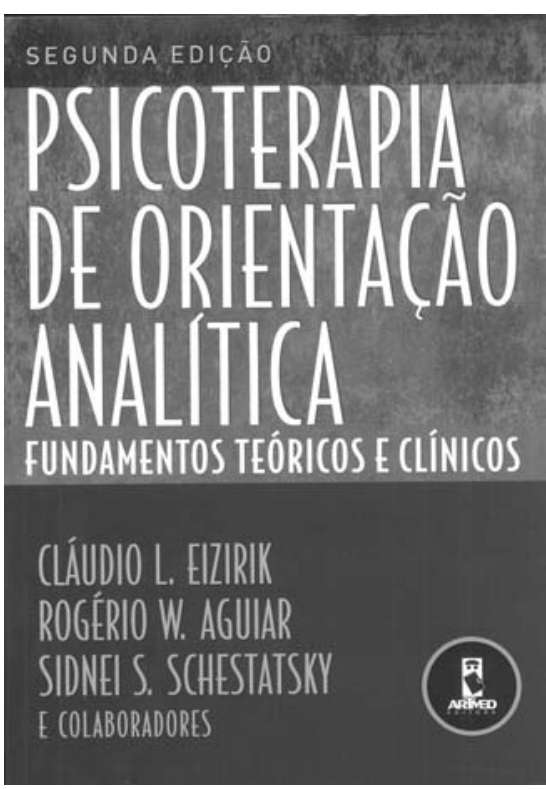

interlocução. Eram colegas com os quais eu me identificava na formação, prática clínica e docência da psicoterapia de orientação psicanalítica, visto que eram profissionais que trabalhavam com as delimitações e as orientações objetivas e claras do campo.

Não podemos esquecer também que, desde a década de 50, tanto a Universidade quanto algumas instituições de atendimento já desenvolviam a prática da psicoterapia de orientação analítica (POA) no Rio Grande do Sul.

Em função dessa tradição do estudo e da aplicação dessa psicoterapia, em 1989 surgiu a primeira edição deste livro, elaborada pelo grupo de professores da Universidade Federal do Rio Grande do Sul (UFRGS), que possibilitou aos psicoterapeutas do Brasil aprofundar, melhor conhecer e sistematizar a POA. Logo ela se tornou uma importante referência nesse campo, por sua inegável qualidade.

Passados 15 anos, surge esta segunda edição. Se a primeira foi um marco como referência, o que poderemos dizer desta?

Num manuseio inicial, em uma visão macro, folheando e lendo o nome dos autores e dos colaboradores regionais, nacionais e internacionais, compreende-se estar diante de um livro que apresenta uma discussão

* Psiquiatra e psicoterapeuta. Fundador e docente do curso de Formação em Psicoterapia Psicodinâmica do Instituto Sedes Sapientiae de São Paulo (1976). Coordenador do Departamento de Psicoterapia da Associação Brasileira de Psiquiatria. Diretor da Associação Brasileira de Psicoterapia. 
globalizada do conhecimento científico atual sobre a psicoterapia de orientação psicanalítica. Nesse sentido, entendo-o como um novo livro legitimando pragmaticamente este campo e, conseqüentemente, seu estado-da-arte.

A análise dos títulos que constam de cada parte do livro e dos autores que escreveram os capítulos - estes, especialistas em suas áreas -, confirma a qualidade e a contemporaneidade dos textos. Escrito numa linguagem clara e objetiva, pode ser útil e apreciado tanto por profissionais como por leigos na área, o que marca um grande diferencial entre inúmeras publicações.

A Parte I - Temas introdutórios nos localiza no campo da psicoterapia. Temos uma revisão feita por autores que representam o atual campo mundial da psicanálise, da psiquiatria e da POA.

O Dr. Michael Stone apresenta uma síntese da história da psicoterapia, afirmando que esta, em seus aspectos fundamentais, já existia muito antes da existência de qualquer disciplina chamada "psiquiatria". Conclui dizendo "que estamos nos encaminhando à consolidação e integração na esfera da psicoterapia, em oposição ao forte sectarismo existente entre as escolas no século XX". Os capítulos 2 e 3 se propõem a discorrer e situar as raízes históricas da psicanálise e da POA até a situação atual ( $R$. S. Wallerstein) e sua relação com ciência e conhecimento (J. L. Ahumada). No capítulo 4, R. Bernardi apresenta reflexões que objetivam a investigação dos processos racionais e emocionais que orientam as preferências e as mudanças dos analistas em suas idéias teóricas e técnicas.

A Parte II - Fundamentos teóricos e técnicos da $P O A$ nos conduz à interface feita através do rastreamento dos vários autores do campo psicanalítico (metapsicologia), com aplicação no campo da psicoterapia psicanalítica.

Seguindo o eixo psicanalítico, são apresentadas as premissas desde Freud (L.C. Mabilde), seguido da importância do trauma interno e externo tanto na teoria quanto na prática (Norberto C. Marucco); os conceitos das escolas das relações objetais entendidos contemporaneamente (E. M. R. Barros) ao objeto de estudo da psicanálise e sua ligação com o objeto de estudo das neurociências (M. Solms); as teorias sobre a ação terapêutica da POA e suas origens nas idéias sobre os mecanismos de ação da psicanálise, seguindo o eixo Freud-Klein-Bion (V. S. Mondrzak), e a reflexão acerca de algumas tendências de evolução nas diferentes abordagens sobre a situação terapêutica, as quais delineiam os conceitos de campo e intersubjetividade (P. H. Cavalli); a forma como a psicoterapia e a psicanálise trabalham com a realidade interna e a realidade psíquica ( $D$.Widlocher), seguida das reflexões sobre mundo interno e transformações (J. C. Carlich); e, finalmente, modelos psicanalíticos da mente cujo objetivo é introduzir o estudo dos modelos teóricos (J. C. Carlich).

Os 16 capítulos que compõem a Parte III Fundamentos da técnica psicoterápica de orientação analítica nos remetem a uma profunda reflexão sobre os fundamentos, as características e os senões da abordagem técnica da POA, brindando os leitores com uma visão ampla, atualizada e universal sobre algumas das questões mais relevantes dessa temática.

Os quatro capítulos iniciais desta parte referem-se ao que poderíamos denominar de "eixo técnico" de uma POA. C. E. Keidan e J. S. Dal Zot iniciam convidando o leitor à reflexão sobre como deve ser feita a avaliação de um paciente. E. lankilevich dedica-se a um dos diferenciais técnicos da POA: o planejamento da psicoterapia. No capítulo 16, M. H. G. Valério trata da importância do foco na psicoterapia e de como fazer sua delimitação. N. K. Lucion e L. Knijnik abordam o tema do contrato e suas vicissitudes, entendendo-os como parte do processo psicoterápico.

Os 11 capítulos restantes abordam aspectos do relacionamento terapêutico. I. Pechansky dedica-se a uma discussão sobre a controvertida atitude neutra do terapeuta. F. G. Gomes discorre sobre a importância do estabelecimento de sólida aliança terapêutica (AT), caracterizada como a relação positiva e necessária entre terapeuta e paciente. No capítulo 20, A. B. Luz examina as peculiaridades da psicoterapia analiticamente orientada sob 0 ângulo dos fenômenos que determinam momentos específicos de seu desenvolvimento. R. Levy traça uma linha histórica do desenvolvimento do conceito de insight e do uso da palavra no tratamento psicanalítico. Os dois capítulos seguintes são partes indissociáveis do tema: transferência e contratransferência. R. Tyson e C. L. Eizirik dedicam-se à transferência, definida como "fenômeno universal e a parte mais difícil do tratamento" (Bird). Já C. L. Eizirik e S. Lewkowicz buscam descrever criticamente as diferentes fases da evolução do conceito de contratransferência. No capítulo 24, G. O. Gabbard trata das violações de fronteiras profissionais nos relacionamentos terapêuticos, 
considerando-as como uma "margem" ou um limite do comportamento adequado do psicoterapeuta psicanalítico na situação clínica. Com referência aos fenômenos de atuações e encenações no tratamento psicanalítico e psicoterápico, M. Gus lembra a importância da compreensão da realidade psíquica colocada em cena pela dupla, por meio do acting e do enactment. A. C. J. Pires trata das vicissitudes do processo psicoterápico, em especial, da reação terapêutica negativa (RTN) e do impasse. P. F. B. Soares trata da comunicação do paciente, das formas de entender essa comunicação e da intervenção. No capítulo 28, J. Guedes Cruz revisa alguns aspectos da origem, estrutura, funções e utilização clínica dos sonhos. Com o capítulo 29, R. Romanowski, J. R. Escobar, R. E. Sordi e M. S. Campos fecham a Parte III tratando dos níveis de mudança e dos critérios de melhora em psicoterapia, que devem ser concebidos dentro de parâmetros possíveis e aceitáveis.

A Parte IV - Situações especiais instiganos, de forma quase obrigatória, à reflexão sobre o campo. O psicoterapeuta atual necessita ter uma visão ampla, atualizada e universal de questões emergentes nas quais se baseiam os novos paradigmas científicos, socioculturais, políticos e econômicos da contemporaneidade.

G. Vollmer FI. e G. I. Berlim procuram estabelecer uma ligação entre ética e psicoterapia, alegando que, subjacente ao sintoma psíquico e ao estado de sofrimento psíquico, há um conflito ético e, determinante deste, um conflito psíquico. Nos capítulos 31 ("Contribuições psicodinâmicas à psicoterapia de apoio", de L. H. F. Ceitlin e G. G. Manfro), 32 ("Psicoterapia e psicofarmacologia", de C. M. S. Osório e M. P. A. Fleck) e 33 ("Estudo sobre a efetividade de psicoterapia”, de Peter Fonagy), evidencia-se a necessidade do psicoterapeuta estar atualizado diante do científico. Exemplos incluem: o entendimento de que psicoterapia de apoio exige conhecimentos de todo referencial psicanalítico e de que as intervenções de apoio estão presentes em todas as modalidades de psicoterapia e psicanálise padrão; a associação da psicofarmacoterapia à psicoterapia na prática clínica, suas indicações, complexidades e controvérsias; a análise da efetividade das intervenções psicossociais para os principais quadros psiquiátricos, através de revisões de estudos baseados em evidências e de estudos controlados randomizados. Em "Gênero e psicoterapia”, de M. S. Araújo, e "Uma visão clínica da homossexualidade", de E. S. Person, temos a possibilidade de avaliar o quanto as mudanças socioculturais modificaram o campo clínico da psicoterapia, influenciando o binômio transferência/contratransferência e o campo intersubjetivo, assim como com referência ao conceito de homossexualidade, anteriormente considerada doença e agora vista como normal. J. Zaslavsky e C. L. S. Brito apresentam alguns dos pressupostos teóricos e técnicos para o ensino de POA na atualidade.

Na Parte V - Fundamentos das abordagens psicodinâmicas em situações clínicas específicas nos propicia aprofundar a compreensão da prática clínica da POA nas principais entidades nosológicas.

Em "O que tratamos em psicoterapia?", M. H. G. Valério, através de um exemplo clínico hipotético e suas possíveis evoluções, indicanos os passos que podemos adotar para que o paciente tome contato afetivo com suas doenças. M. P. Santos, H. O. Fontouro e C. Gari tratam dos aspectos relevantes do caráter ou de seus traços no que tange à sua origem e desenvolvimento em suas manifestações durante o tratamento. R. Cassorla trata da abordagem da ansiedade e seus sintomas, sem fazer distinção entre psicanálise e psicoterapia psicanalítica, por considerá-las um continuum. S. L. P. Machado e S. Schestatsy confirmam os conceitos teóricos de etiologia e da patogenia da depressão. J. A. Nogueira desenvolve o transtorno de personalidade histriônica a partir de histórico desde Hipócrates até o advento da psicanálise, descrevendo, então, o ponto de vista psicodinâmico. Em "Abordagem do paciente obsessivo", J. J. Chachamovich e I. C. Fetter trazem um histórico do tema, citando Freud, Klein, Liberman e outros autores, diferenciando transtorno obsessivo-compulsivo do transtorno de personalidade obsessivo-compulsiva. $\mathrm{H}$. Ferrari, escrevendo sobre fobias e o tratamento psicanalítico das mesmas, esclarece que a fobia funciona como uma defesa que evita o desenvolvimento da angústia ou de ataques de pânico. S. Lewkowicz destaca contribuições fundamentais para a compreensão do narcisismo. Nos capítulos 45 e 46, respectivamente, S. S. Schestatsy e O. F. Kemberg discutem a patologia borderline. $\mathrm{O}$ primeiro, ao tratar o conceito borderline, referese ao status diagnóstico e psicodinâmico do paciente e a sua analisabilidade. O segundo trata das explosões emocionais ou "tempestades afetivas" de pacientes com organização de personalidade borderline e grave regressão na transferência. R. Hartke conceitua e examina aspectos teóricos e técnicos da perversão como 
um fenômeno que pode manifestar-se na relação terapêutica. M. Aisenstein relembra a unidade psicossomática do ser humano. H. L. Persano trata dos transtornos alimentares, sendo o tratamento psicanalítico, na evolução em longo prazo, útil nesses casos, de preferência numa abordagem multidisciplinar e integradora. R. W. Aguiar e L. Calefi tratam da abordagem do paciente com dor crônica e das condições requeridas para seu atendimento, como avaliação abrangente e o desenvolvimento de um tratamento interdisciplinar. C. Garland mostra a importância e o valor de um entendimento psicoterápico no impacto do trauma sobre o funcionamento mental e sobre a personalidade. M. L. S. Zavaschi, A. M. S. Bassols, D. S. Bergmann e F. M. C. Costa apresentam alguns fundamentos da teoria e da técnica da POA aplicada em crianças, sendo o referencial utilizado a teoria kleiniana. A. B. Lewkowicz e G. Brodacz falam sobre o tratamento de adolescentes dentro do contexto sociocultural atual. A. M. Rosa e M. C.Vasconcellos tratam da abordagem psicodinâmica do paciente geriátrico, levando em consideração o conceito de velhice atual. C. A. Krieger e A. Cataldo Neto recordam que o paciente que precisa de internação é atendido por uma equipe de profissionais de diferentes áreas. A psicoterapia desses pacientes deve obedecer à avaliação sistemática e à compreensão da fenomenologia psicanalítica dos mecanismos envolvidos. F. Pechansky e L. Luborsky apresentam o tratamento do paciente dependente químico.

Finalizando esta resenha, concluímos que este livro atinge seu objetivo, tornando-se referência atualizada e obrigatória sobre psicoterapia de orientação psicanalítica para todos os profissionais que lidam com saúde mental.

Title: Review of the book entitled Psicoterapia de orientação analítica: fundamentos teóricos e clínicos

Título: Reseña del libro Psicoterapia de orientação analítica: fundamentos teóricos e clínicos

E-mail: jtthome@uol.com.br

Copyright (C) Revista de Psiquiatria do Rio Grande do Sul - SPRS 